\title{
Virtual Reality Rehabilitation in Patients with Chronic Obstructive Pulmonary Disease: A Randomized Controlled Trial
}

This article was published in the following Dove Press journal: International Journal of Chronic Obstructive Pulmonary Disease

\author{
Sebastian Rutkowski (iD) \\ Anna Rutkowska (iD) \\ Paweł Kiper $\mathbb{D}^{2}$ \\ Dariusz Jastrzebski $\mathbb{1}^{3}$ \\ Henryk Racheniuk (D) \\ Andrea Turolla $\mathbb{D D}^{2}$ \\ Jan Szczegielniak (1D) \\ Richard Casaburi (iD) ${ }^{4}$ \\ 'Institute of Physiotherapy, Department \\ of Physical Education and Physiotherapy, \\ Opole University of Technology, Opole, \\ Poland; ${ }^{2}$ Laboratory of \\ Neurorehabilitation Technologies, \\ Fondazione Ospedale San Camillo \\ IRCCS, Venice, Italy; ${ }^{3}$ School of Medicine \\ with the Division of Dentistry, \\ Department of Lung Diseases and \\ Tuberculosis, Medical University of \\ Silesia, Zabrze, Poland; ${ }^{4}$ Los Angeles \\ Biomedical Research Institute at Harbor- \\ UCLA Medical Center, Torrance, \\ CA, USA
}

Correspondence: Sebastian Rutkowski Institute of Physiotherapy, Department of Physical Education and Physiotherapy, Opole University of Technology, Opole, Poland

Tel +48 507027792

Fax +48 774498000

Email s.rutkowski@po.opole.pl
Purpose: This study compared the effects of inpatient-based rehabilitation program of patients with chronic obstructive pulmonary disease (COPD) using non-immersive virtual reality (VR) training with a traditional pulmonary rehabilitation program. The aims of this study were to determine 1) whether rehabilitation featuring both VR as well as exercise training provides benefits over exercise training (ET) alone and 2) whether rehabilitation featuring VR training instead of exercise training provides equivalent benefits.

Patients and Methods: The study recruited 106 patients with COPD to a 2-week highintensity, five times a week intervention. Randomized into three groups, 34 patients participated in a traditional pulmonary rehabilitation program including endurance exercise training (ET), 38 patients participated in traditional pulmonary rehabilitation, including both endurance exercise training and virtual reality training $(\mathrm{ET}+\mathrm{VR})$ and 34 patients participated in pulmonary rehabilitation program including virtual reality training but no endurance exercise training (VR). The traditional pulmonary rehabilitation program consisted of fitness exercises, resistance respiratory muscle and relaxation training. Xbox $360^{(\mathbb{R}}$ and Kinect ${ }^{(\mathbb{R}}$ Adventures software were used for the VR training of lower and upper body strength, endurance, trunk control and dynamic balance. Comparison of the changes in the Senior Fitness Test was the primary outcome. Analysis was performed using linear mixed-effects models.

Results: The comparison between ET and ET+VR groups showed that ET+VR group was superior to ET group in Arm Curl ( $p<0.003)$, Chair stand $(p<0.008)$, Back scratch $(p<0.002)$, Chair sit and reach $(p<0.001)$, Up and go $(p<0.000), 6$-min walk test $(p<0.011)$. Whereas, the comparison between ET and VR groups showed that VR group was superior to ET group in Arm Curl $(\mathrm{p}<0.000)$, Chair stand $(\mathrm{p}<0.001), 6$-min walk test $(\mathrm{p}<0.031)$.

Conclusion: Results suggest that pulmonary rehabilitation program supplemented with VR training is beneficial intervention to improve physical fitness in patients with COPD.

Keywords: virtual reality, $\mathrm{COPD}$, pulmonary rehabilitation, physical activity, exercise

\section{Introduction}

Based on the reports of the American Thoracic Society and the European-Respiratory Society, chronic obstructive pulmonary disease (COPD) is the third leading cause of mortality worldwide. ${ }^{1}$ COPD symptoms include not only shortness of breath, chronic cough, and sputum production, but also reduced exercise tolerance. ${ }^{2-6}$ Traditional programs of pulmonary rehabilitation have been shown to be capable of at least partially reversing muscle dysfunction and improving mobility; it is the most effective therapy to improve exercise tolerance in chronic respiratory diseases, ${ }^{7,8}$ idiopathic pulmonary 
fibrosis, ${ }^{9}$ and lung cancer. ${ }^{10}$ However, in international surveys, traditional pulmonary rehabilitation is available to only a small fraction of COPD patients. ${ }^{11}$ Alternate modes of rehabilitation are sought which might increase availability to patients who would benefit. Virtual reality (VR) technologies have been explored as a possible adjunct to physical rehabilitation programs. ${ }^{12-20}$ An example of such technology is the use of biofeedback in the form of VR games wherein patients, by participating in the game, improve motor performance. The advantages of this technology include graded levels of difficulty, ability to monitor task duration and intensity, provision of feedback on errors, and provision of tips and guidance on the movements performed. ${ }^{21}$

To date, no studies have reported the results of pulmonary rehabilitation programs incorporating virtual reality techniques via the $\operatorname{Kinect}^{\circledR}$ system in patients with COPD. Therefore, we developed a rehabilitation program based on non-immersive virtual reality training, applied it to patients with COPD and evaluated the effects of such rehabilitation in an inpatient hospital unit in comparison with traditional pulmonary rehabilitation (TPR). The aims of this study were to determine 1) whether rehabilitation featuring both VR as well as exercise training provides benefits over exercise training (ET) alone and 2) whether rehabilitation featuring VR training instead of exercise training provides equivalent benefits.

\section{Materials and Methods}

\section{Participants}

This study enrolled 120 patients diagnosed as having COPD from the Specialist Hospital in Głuchołazy, Poland, between
August 2015 and November 2016 (Table 1). ${ }^{22}$ Data obtained from the 106 patients who completed the study were used in the analysis (Figure 1). All patients signed a written informed consent prior to their participation in the study. Patients who meet the inclusion criteria were randomly assigned to one of the three experimental groups described below. Randomization (ratio 1:1:1) was performed using the Research Randomizer, a web-based service that offers instant random assignment. Sealed envelopes were used for group assignment. The study was scheduled by a physiotherapist from the Institute of Physiotherapy, not related to the hospital, who generated the random allocation sequence to be included in the appropriate study group. The inclusion criteria were as follows: 1) female and male aged between 50 and 70 years and 2) patients with Global Initiative for Chronic Obstructive Lung Disease (GOLD) 2 and 3 spirometric stages. The exclusion criteria were as follows: 1) no provision of consent to participate; 2) pneumonia, tuberculosis, and other respiratory inflammatory disease; 3) less than 6-months post-myocardial infarction; 4) insulin-dependent diabetes mellitus; 5) less than 6-months post thoracic or cardiac surgery 6) heart failure (NYHA stage III or IV); 7) advanced uncontrolled hypertension; 8) diseases and injuries that impair the function of the musculoskeletal system of mobility; 9) cognitive disorders and Mini-Mental State Examination score $<24$. The study adhered to the Declaration of Helsinki and ethical approval was obtained by the Bioethical Commission of the Opole Chamber of Physicians (Resolution No. 199 of February 7, 2013) and was retrospectively registered in the Australian New Zealand Clinical Trials Registry: ACTRN12617000275369. The data collected from human subjects were collected,

Table I Characteristics of the Patients

\begin{tabular}{|l|l|l|l|l|}
\hline & ET $\mathbf{n}=\mathbf{3 4}$ & ET+VR $\mathbf{n}=38$ & VR $\mathbf{n = 3 8}$ & Between-Group Comparison p-value* \\
\hline Men, $\mathrm{n}$ & 18 & 19 & 10 & $\mathrm{p}>0.05$ \\
\hline Women, $\mathrm{n}$ & 16 & 19 & 28 & $\mathrm{P}>0.05$ \\
\hline Age, years (SD) & $62.1 \pm 2.9$ & $60.6 \pm 4.3$ & $60.4 \pm 4.2$ & $\mathrm{P}>0.05$ \\
\hline BMI, kg/m & $25.3 \pm 4$ & $24.2 \pm 4$ & $23.5 \pm 3$ & $\mathrm{P}>0.05$ \\
\hline Group B/C & $17 / 17$ & $19 / 19$ & $19 / 19$ & $\mathrm{P}>0.05$ \\
\hline Spirometry parameters & & & & \\
FVC, (\% pred) & $79.5 \pm 23.8$ & $73.2 \pm 13.9$ & $82.6 \pm 17.5$ & $\mathrm{P}>0.05$ \\
FEV, (\% pred) & $65.4 \pm 24.0$ & $60.5 \pm 16.2$ & $69.2 \pm 23.6$ & $\mathrm{P}>0.05$ \\
FEV,$\%$ FVC & $66.1 \pm 13.6$ & $65.8 \pm 16.2$ & $66.9 \pm 16.0$ & $\mathrm{P}>0.05$ \\
\hline
\end{tabular}

Notes: *The ANOVA Kruskal-Wallis; \% pred, predicted values from Viljanen ${ }^{22}$.

Abbreviations: SD, standard deviation; BMI, body mass index; FVC, forced vital capacity; FEV 


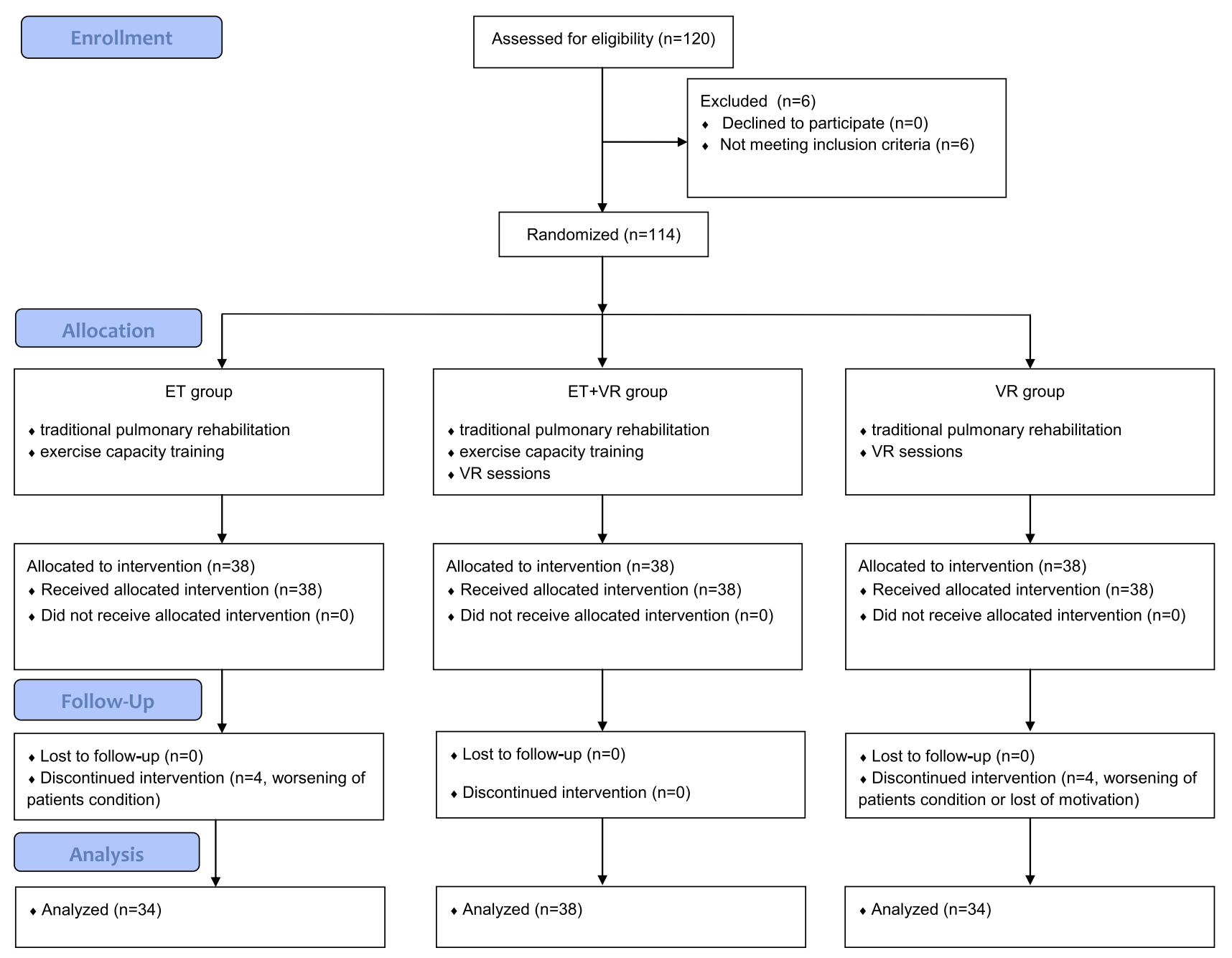

Figure I CONSORT 2010 Flow Diagram.

Abbreviations: $E T$, endurance training; $E T+V R$, endurance training + virtual reality training; $V R$, virtual reality training.

managed and protected by research team and hospital staff members. This trial was designed as an assessor-blinded, parallel-group study.

\section{Design}

The patients in the ET group participated in a TPR program and endurance exercise training sessions. Patients in the ET +VR group participated in a TPR, as well as both endurance exercise training and VR sessions using the Kinect ${ }^{\circledR}$ system. Patients in VR group participated in a TPR and VR sessions.

\section{Interventions}

\section{The Traditional Pulmonary Rehabilitation Program}

Components were performed once a day, each for 15-30 min (depending on the task), five times a week for 2 weeks. Exercises were performed as follow:
- Fitness exercises, coordination and balance exercises and stretching exercises using elastic tapes, rehabilitation balls, and sensory cushions. Exercises were performed in the following positions: standing, on the knees, and lying on the side, abdomen, and back.

- Specific respiratory exercises for 30 mins: relaxation exercises for breathing muscles, strengthening exercises of the diaphragm with resistance, exercises to increase costal or chest breathing, prolonged exhalation exercise, and chest percussion. ${ }^{23}$

- Group walks with a physiotherapist around the hospital.

- Inhalation with a $3 \% \mathrm{NaCl}$ isotonic solution administered with an ultrasonic device.

- Rapidly changing postural drainage positions and chest percussions by a physiotherapist.

- Relaxation training, 15 min a day. 


\section{Endurance Exercise Training}

Stationary cycle ergometer exercise was performed for 20-30 min, five times a week, to obtain a training heart rate, which was calculated as follows: heart rate [ $\max \mathrm{HR}$ - resting HR $) \times(60$ or 70$) \%]+$ resting HR through the use of the results of the 6-min walk test. ${ }^{24}$ The percentage values were $70 \%$ to GOLD 2 spirometric stages patients and $60 \%$ for GOLD 3 spirometric stages patients. The training were performed under the supervision of a physiotherapist; the heart rate was monitored continuously.

\section{VR Sessions}

The setup consisted of the console (Xbox $360^{\circledR}$ ), a motion sensor $\left(\right.$ Kinect $\left.^{\circledR}\right)$, and a projector with speakers. The height of the console, which was placed on a table, was $1 \mathrm{~m}$. The Kinect ${ }^{\circledR}$ motion sensor was placed on the projector, which projected images on a wall located $2.5 \mathrm{~m}$ away from the playing area. The playing area was at least $1.8 \mathrm{~m}$ wide and $1.8 \mathrm{~m}$ long and was located $1.2 \mathrm{~m}$ from the Kinect ${ }^{\circledR}$ sensor. Before starting each training session, the device was calibrated to correctly follow the movements of each patient.

The intensity-controlled VR sessions included games provided by the Kinect ${ }^{\circledR}$ Adventures (Microsoft Game Studios, Washington, US). Patients participated in minigames in which they performed certain movements in front of the motion sensor. The games included rafting, cross-country running, hitting a ball in the direction of a player on the screen, and a mountain wagon ride. Before each game, the manufacturer's instructions were displayed, indicating the goal of the game and the method of the avatar control. Kinect ${ }^{\circledR}$ training involved four games: 20,000 Leaks, Curvy Creek, Rally Ball, and Reflex Ridge. In 20,000 Leaks game, movement tasks were focused on improving agility, dynamic balance, strengthening the lower and upper limbs and improving endurance. In the Curvy Creek game, tasks were focused on improving the elasticity of the lower body, balance and strengthening the lower limbs and improving endurance. In the Rally Ball game, tasks were focused on improving the elasticity of the upper body, strengthening the upper and lower limbs, improving the dynamic balance and improving endurance. In the Reflex Ridge game, movement tasks were focused on improving flexibility of the upper and lower body, coordination while avoiding obstacles and improving the strength of the lower limbs, agility, balance and endurance. $^{25}$

In each of these games, patients were instructed to score as many points as possible for both quantitative and qualitative achievements. Throughout the training, heart rate was monitored to ensure that patients did not exceed their age-predicted maximal heart rate $(208-0.7 \mathrm{x}$ age $){ }^{26}$ The therapeutic session was set individually and performed for about $20 \mathrm{~min}$. During the session each patient participated in the four games in the same order in each session, 5 days a week with the same workloads. The VR training was supervised by a physiotherapist.

\section{Outcome Measures}

Assessments were performed at the beginning and at the end of the rehabilitation program, i.e., after 2 weeks. The Senior Fitness Test (also known as the Fullerton test) was used to assess physical fitness as a primary outcomes. ${ }^{27}$ Six-motor tasks are evaluated, including strength, endurance, flexibility, agility, aerobic capacity, balance, and motor coordination.

- Arm curl - to assess the strength of the upper body calculated as repetitions.

- Chair stand- to assess the strength of the lower body calculated as repetitions.

- Back scratch - to assess the flexibility of the upper body calculated in centimeters.

- Chair sit and reach- to assess the flexibility of the lower body calculated in centimeters.

- Up and go - to assess agility and dynamic balance calculated in seconds.

- 6-min walk test (6MWT) - to assess exercise performance calculated in meters.

\section{Statistical Analysis}

A linear-mixed effects analysis was performed to investigate and assess effects of the intervention on the outcome measures. As a fixed effects group, model and time (with interaction terms) were entered into the model. Intercepts for patients were used as a random effect. Several models were built for each dependent variable; the most appropriate was chosen according to Akaike Information Criteria value. A $p$ value $<0.05$ was regarded as statistically significant. All calculations were performed using $\mathrm{R}$ Statistical Computing software ver. 3.3.2 (R Core Team 2017, R Foundation for Statistical Computing, Vienna, Austria). The sample size was determined a priori using $G^{*}$ power 3.1.6 software. Calculation was based on the $F$-test with type I error rate set at $5 \%$, the effect size at 0.30 , and type II error rate at $85 \%$ power. Assuming a $15 \%$ drop-out rate, the minimum sample size for this study was 96 subjects. 


\section{Results}

The analyzed data were obtained from 106 patients. After randomization, eight patients discontinued the study intervention due to worsening of their condition or loss of motivation (Figure 1). All other patients completed studies with a participation of more than $95 \%$ rate.

\section{Pre-Post Group Analysis}

The analysis of the data showed a significant improvement in all six components of the Senior Fitness Test in all tested groups, except Chair sit and reach as well as the Up and go variable in ET group (Table 2). In the VR and $\mathrm{ET}+\mathrm{VR}$, the improvement in 6MWT exceeded the postulated threshold of minimum clinical important difference ( $\sim 30$ meters $)$.

\section{Between-Group Comparison}

In all six Senior Fitness Test components, improvements in ET+VR were statistically significantly superior to ET (Table 3). Thus, patients exposed to reinforced feedback which was provided during VR sessions, made better improvement than those treated traditionally.
The comparison between ET and VR groups showed that in 3 of 6 components (Arm curl, Chair stand and, importantly, $6 \mathrm{MWT}$ ), VR was statistically significantly superior to ET. In three components, differences failed to achieve significance (Back scratch, Chair sit and reach and Up and go) (Table 3).

\section{Discussion}

Current international guidelines recommend a minimum length of 6 weeks for a pulmonary rehabilitation program, indicating a higher efficacy of programs with a longer duration. However, in some countries, eg, Poland, Germany the length of the program is limited to 3 weeks by the majority of insurance companies or national health funds. ${ }^{28}$ To the best of our knowledge, this is the first analysis of patients with moderate and severe COPD undergoing an intensive twoweek hospital-based rehabilitation program using virtual rehabilitation training. In this two-week, inpatient rehabilitative intervention, significant increases in all components of the Senior Fitness test were seen in each of the three study groups. Rehabilitation incorporating a Virtual Reality component yielded superior improvements in three of the six

Table 2 Parameters of the Senior Fitness Test, Within Group Comparison

\begin{tabular}{|c|c|c|c|c|c|}
\hline \multirow[t]{2}{*}{ Variable } & \multirow[t]{2}{*}{ Group } & \multirow{2}{*}{$\begin{array}{l}\text { Baseline } \\
\text { LS Means } \\
\text { (Lower CL - Upper CL) }\end{array}$} & \multirow{2}{*}{$\begin{array}{l}\text { Post-Rehabilitation } \\
\text { LS Means } \\
\text { (Lower CL - Upper CL) }\end{array}$} & \multicolumn{2}{|l|}{ Change } \\
\hline & & & & Difference $( \pm$ SE) & p-Value \\
\hline Arm curl [rep.] & $\begin{array}{l}E T \\
E T+V R \\
V R\end{array}$ & $\begin{array}{l}\mid 8.97(\mid 7.88-20.06) \\
|8.7|(\mid 7.68-19.74) \\
2 \mid(|9.9|-22.09)\end{array}$ & $\begin{array}{l}20.32(19.24-21.4 I) \\
21.97(20.95-23) \\
25.65(24.56-26.73)\end{array}$ & $\begin{array}{l}1.35( \pm 0.47) \\
3.26( \pm 0.44) \\
4.65( \pm 0.47)\end{array}$ & $\begin{array}{l}0.005 \\
0.000 \\
0.000\end{array}$ \\
\hline Chair stand [rep.] & $\begin{array}{l}E T \\
E T+V R \\
V R\end{array}$ & $\begin{array}{l}14.76(13.65-15.88) \\
14.6 \mid(13.55-15.66) \\
16.35(15.24-17.47)\end{array}$ & $\begin{array}{l}15.59(14.47-16.7) \\
16.89(15.84-17.95) \\
18.97(17.85-20.09)\end{array}$ & $\begin{array}{l}0.82( \pm 0.4) \\
2.29( \pm 0.38) \\
2.62( \pm 0.4)\end{array}$ & $\begin{array}{l}0.043 \\
0.000 \\
0.000\end{array}$ \\
\hline Back scratch $[\mathrm{cm}]$ & $\begin{array}{l}E T \\
E T+V R \\
V R\end{array}$ & $\begin{array}{l}-7.86(-10.98--4.73) \\
-6.26(-9.2--3.32) \\
-4.88(-7.99--1.77)\end{array}$ & $\begin{array}{l}-7.12(-10.24--4) \\
-4.22(-7.16--1.28) \\
-3.53(-6.64--0.42)\end{array}$ & $\begin{array}{l}0.74( \pm 0.3) \\
2.04( \pm 0.28) \\
1.35( \pm 0.3)\end{array}$ & $\begin{array}{l}0.016 \\
0.000 \\
0.000\end{array}$ \\
\hline Chair sit and reach $[\mathrm{cm}]$ & $\begin{array}{l}E T \\
E T+V R \\
V R\end{array}$ & $\begin{array}{l}0.03(-2.5-2.56) \\
0.53(-1.86-2.92) \\
2.87(0.34-5.39)\end{array}$ & $\begin{array}{l}0.44(-2.08-2.97) \\
3.2(0.81-5.59) \\
4.43(1.9-6.95)\end{array}$ & $\begin{array}{l}0.4 \mathrm{I}( \pm 0.5 \mathrm{I}) \\
2.67( \pm 0.48) \\
1.56( \pm 0.5 \mathrm{I})\end{array}$ & $\begin{array}{l}0.417 \\
0.000 \\
0.003\end{array}$ \\
\hline Up and go [s] & $\begin{array}{l}E T \\
E T+V R \\
V R\end{array}$ & $\begin{array}{l}6.36(6.03-6.68) \\
6.01(5.7-6.3 I) \\
5.84(5.5 I-6.16)\end{array}$ & $\begin{array}{l}6.18(5.86-6.5) \\
5.26(4.96-5.57) \\
5.46(5.14-5.79)\end{array}$ & $\begin{array}{l}-0.18( \pm 0.09) \\
-0.74( \pm 0.09) \\
-0.37( \pm 0.09)\end{array}$ & $\begin{array}{l}0.065 \\
0.000 \\
0.000\end{array}$ \\
\hline 6 min walk test $[\mathrm{m}]$ & $\begin{array}{l}E T \\
E T+V R \\
V R\end{array}$ & $\begin{array}{l}492.07(479.39-504.74) \\
471.53(459.58-483.47) \\
487.91(475.29-500.54)\end{array}$ & $\begin{array}{l}508.3(495.63-520.97) \\
510.63(498.69-522.57) \\
523.38(510.76-536.01)\end{array}$ & $\begin{array}{l}16.24( \pm 6.47) \\
39.11( \pm 6.12) \\
35.47( \pm 6.47)\end{array}$ & $\begin{array}{l}0.014 \\
0.000 \\
0.000\end{array}$ \\
\hline
\end{tabular}

Abbreviations: LS mean, Least Squares Means; CL, confidence level; SE, standard errors; $E T$, endurance training; $E T+V R$, endurance training + virtual reality training; VR, virtual reality training. 
Table 3 Components of the Senior Fitness Test, Between Group Comparison

\begin{tabular}{|c|c|c|c|c|c|c|c|}
\hline \multirow[t]{2}{*}{ Variable } & \multirow[t]{2}{*}{ Group } & \multicolumn{2}{|c|}{ First Measurement } & \multicolumn{2}{|c|}{ Second Measurement } & \multicolumn{2}{|l|}{ Second - First } \\
\hline & & Difference ( \pm SE) & p-Value & Difference ( \pm SE) & p-Value & Difference $( \pm \mathrm{SE})$ & p-Value \\
\hline \multirow[t]{2}{*}{ Arm curl [rep.] } & ET vs ET+VR & $-0.26( \pm 0.76)$ & 0.937 & $1.65( \pm 0.76)$ & 0.078 & $1.91( \pm 0.63)$ & 0.003 \\
\hline & ET vs VR & $2.03( \pm 0.78)$ & 0.027 & $5.32( \pm 0.78)$ & 0 & $3.29( \pm 0.65)$ & 0.000 \\
\hline \multirow[t]{2}{*}{ Chair stand [rep.] } & ET vs ET+VR & $-0.16( \pm 0.78)$ & 0.977 & $1.31( \pm 0.78)$ & 0.216 & $1.47( \pm 0.55)$ & 0.008 \\
\hline & ET vs VR & $1.59( \pm 0.8)$ & 0.119 & $3.38( \pm 0.8)$ & 0 & $1.79( \pm 0.56)$ & 0.001 \\
\hline \multirow[t]{2}{*}{ Back scratch $[\mathrm{cm}]$} & ET vs ET+VR & $1.59( \pm 2.17)$ & 0.743 & $2.9( \pm 2.17)$ & 0.378 & I. $3( \pm 0.4 \mathrm{I})$ & 0.002 \\
\hline & ET vs VR & $2.97( \pm 2.22)$ & 0.378 & $3.59( \pm 2.22)$ & 0.244 & $0.62( \pm 0.42)$ & 0.133 \\
\hline \multirow[t]{2}{*}{ Chair sit and reach $[\mathrm{cm}]$} & ET vs ET+VR & $0.5( \pm 1.76)$ & 0.957 & $2.76( \pm 1.76)$ & 0.263 & $2.26( \pm 0.69)$ & 0.001 \\
\hline & ET vs VR & $2.84( \pm I .8)$ & $0.26 \mathrm{I}$ & $3.99( \pm 1.8)$ & 0.074 & $1.15( \pm 0.7)$ & 0.097 \\
\hline \multirow[t]{2}{*}{ Up and go [s] } & ET vs ET+VR & $-0.35( \pm 0.22)$ & 0.272 & $-0.92( \pm 0.22)$ & 0 & $-0.57( \pm 0.13)$ & 0.000 \\
\hline & ET vs VR & $-0.52( \pm 0.23)$ & 0.066 & $-0.71( \pm 0.23)$ & 0.007 & $-0.19( \pm 0.13)$ & 0.133 \\
\hline \multirow[t]{2}{*}{6 min walk test $[\mathrm{m}]$} & $\mathrm{ET}$ vs $\mathrm{ET}+\mathrm{VR}$ & $-20.54( \pm 8.82)$ & 0.055 & $2.33( \pm 8.82)$ & 0.962 & $22.87( \pm 8.78)$ & 0.011 \\
\hline & ET vs VR & $-4.15( \pm 9.06)$ & 0.891 & $15.08( \pm 9.06)$ & 0.222 & $19.24( \pm 9.02)$ & 0.031 \\
\hline
\end{tabular}

Abbreviations: SE, standard errors; ET, endurance training; $E T+V R$, endurance training + virtual reality training; VR, virtual reality training.

components to a program incorporating traditional cycle ergometer exercise.

The analysis within groups showed an improvement in fitness after completing the rehabilitation in all the studied groups. The greatest improvement in the Arm curl and the Chair stand tests, which measure strength of upper and lower limbs, was recorded in VR group. In the remaining SFT variables describing upper and lower body flexibility, balance and exercise performance, the largest improvement was obtained in ET+VR group. In addition, only in ET+VR group, which included all modes of trainings, a statistically significant improvement in all SFT trials were noted. Significant improvement in strength, flexibility and balance has clinical because patients suffering from COPD often limit physical activity, which then results in reduction in exercise tolerance.

The sedentary behaviour of most COPD patients is hard to reverse without the sustained effort of professionals trained in motivational techniques and the support of similarly afflicted patients in group sessions; these are key features of traditional rehabilitation. ${ }^{29}$ In this study, we examined the effects of replacing endurance exercise training by the VR training (VR group). The premise of this change addresses an important problem in rehabilitation: how to motivate COPD patients, who are generally elderly, to perform regular physical fitness exercises at home? This problem becomes real when the patient is discharged from the hospital, returns home and loses regular supervision from hospital's staff. Exercise that is perceived of as a game is much more attractive and gives higher probability that a patient will follow the physiotherapist's prescription. ${ }^{30}$ However, before such regimen is prescribed, it is important to identify games that give superior effects when compared to traditional pulmonary rehabilitation methods. In the present study, it seems especially important that we defined a statistically significant improvement in the exercise performance in VR patients, because it has been assumed that exercise training on a treadmill or bicycle ergometer is necessary to improve exercise performance. This is of practical importance because, after completing the formal phase of rehabilitation, patients using a game console can continue the training ${ }^{31-34}$

The study of LeGear et al showed that the level of physical effort exerted during virtual rehabilitation training is similar to that generated during training on a treadmill. ${ }^{35}$ The study of Wardini et al showed significant changes in heart rate, oxygen saturation, and dyspnea during VR training using the Nintendo Wii ${ }^{\circledR}$ system in patients with COPD. During the training, statistically significant changes in circulatory and respiratory parameters were noted, and the authors concluded that moderate VR exercise is safe and comfortable for patients. These results suggest that these types of exercises can be continued at home. ${ }^{36}$

The strengths of our study include the use of a control group and the substantial number of patients included. Currently, the number of studies using the Kinect system in COPD cases is low. ${ }^{35,36}$ This new methodology might find application in motivating patients with COPD to 
perform regular physical fitness exercises at home. Exercise that is incorporated into a game may yield higher probability that a patient will follow the physiotherapist's prescriptions.

\section{Limitations of the Study}

A limitation of this study was the inclusion of only GOLD 2 and 3 spirometric stages. The study presents findings of the 2-weeks in-hospital pulmonary rehabilitation program. While it might be assumed that results might have been even better if the study had lasted longer, effects of this intervention in longer-term outpatient programs should be studied. In this study, we have not evaluated game-training satisfaction by the standardized questionnaires.

\section{Conclusion}

In this study, hospitalized patients who used a VR rehabilitation system showed improvement in physical fitness in all the Senior Fitness Test components. Hence, this study suggests that a pulmonary rehabilitation program supplemented with virtual rehabilitation training is a beneficial intervention for enhancing physical fitness in patients with COPD.

\section{Abbreviations}

6MWT, 6-min walk test; COPD, chronic obstructive pulmonary disease; ET, exercise training; ET+VR, exercise training and virtual reality training; GOLD, global initiative for chronic obstructive lung disease; NYHA, New York heart association; TPR, traditional pulmonary rehabilitation; VR, virtual reality.

\section{Funding}

The authors thank the Ministry of Science and Higher Education for providing the funding (Opole University of Technology/Faculty of Physical Education and Physiotherapy, project ID DS-MN/07/WW/18).

\section{Disclosure}

The authors report no conflicts of interest in this work.

\section{References}

1. Celli BR, Decramer M, Wedzicha JA, et al. An official American Thoracic Society/European Respiratory Society statement: research questions in COPD. Eur Respir J. 2015;45(4):879-905. doi:10.1183/ 09031936.00009015

2. Al-Shair K, Kolsum U, Singh D, Vestbo J. The effect of fatigue and fatigue intensity on exercise tolerance in moderate COPD. Lung. 2016;194(6):889-895. doi:10.1007/s00408-016-9931-y
3. Langer D, Demeyer H. Interventions to modify physical activity in patients with COPD: where do we go from here? Eur Respir J. 2016;48(1):14-17. doi:10.1183/13993003.00762-2016

4. Pitta F, Troosters T, Spruit MA, Probst VS, Decramer M, Gosselink R. Characteristics of physical activities in daily life in chronic obstructive pulmonary disease. Am J Respir Crit Care Med. 2005;171(9):972-977. doi:10.1164/rccm.200407-855OC

5. Troosters T, Sciurba F, Battaglia S, et al. Physical inactivity in patients with COPD, a controlled multi-center pilot-study. Respir Med. 2010;104(7):1005-1011. doi:10.1016/j.rmed.2010.01.012

6. Watz H, Waschki B, Meyer T, Magnussen H. Physical activity in patients with COPD. Eur Respir J. 2009;33(2):262-272. doi:10.1183/ 09031936.00024608

7. Casaburi R. Pulmonary rehabilitation: where we've succeeded and where we've failed. COPD. 2018;15(3):219-222. doi:10.1080/ 15412555.2018.1503245

8. Spruit MA, Singh SJ, Garvey C, et al. An official American Thoracic Society/European Respiratory Society statement: key concepts and advances in pulmonary rehabilitation. Am J Respir Crit Care Med. 2013;188(8):e13-64. doi:10.1164/rccm.201309-1634ST

9. Nishiyama O, Kondoh Y, Kimura T, et al. Effects of pulmonary rehabilitation in patients with idiopathic pulmonary fibrosis. Respirology. 2008;13(3):394-399. doi:10.1111/j.1440-1843.2007.01205.x

10. Rutkowska A, Jastrzebski D, Rutkowski S, et al. Exercise training in patients with non-small cell lung cancer during in-hospital chemotherapy treatment: a randomized controlled trial. J Cardiopulm Rehabil Prev. 2019;39(2):127-133. doi:10.1097/HCR.0000000000000410

11. Spruit MA, Pitta F, Garvey C, et al. Differences in content and organisational aspects of pulmonary rehabilitation programmes. Eur Respir J. 2014;43(5):1326-1337. doi:10.1183/09031936.00145613

12. Massetti T, Favero FM, Menezes LDC, et al. Achievement of virtual and real objects using a short-term motor learning protocol in people with duchenne muscular dystrophy: a crossover randomized controlled trial. Games Health J. 2018;7(2):107-115. doi:10.1089/g4h.2016.0088

13. Bacha JMR, Gomes GCV, de Freitas TB, et al. Effects of kinect adventures games versus conventional physical therapy on postural control in elderly people: a randomized controlled trial. Games Health J. 2018;7(1):24-36. doi:10.1089/g4h.2017.0065

14. Lee HC, Huang CL, Ho SH, Sung WH. The effect of a virtual reality game intervention on balance for patients with stroke: a randomized controlled trial. Games Health J. 2017;6(5):303-311. doi:10.1089/ g4h.2016.0109

15. Bonnechere B, Jansen B, Omelina L, Van Sint Jan S. The use of commercial video games in rehabilitation: a systematic review. Int $J$ Rehabil Res. 2016;39(4):277-290. doi:10.1097/MRR.0000000000000190

16. Mazzoleni S, Montagnani G, Vagheggini G, et al. Interactive videogame as rehabilitation tool of patients with chronic respiratory diseases: preliminary results of a feasibility study. Respir Med. 2014;108 (10):1516-1524. doi:10.1016/j.rmed.2014.07.004

17. Kiper P, Szczudlik A, Agostini M, et al. Virtual reality for upper limb rehabilitation in subacute and chronic stroke: a randomized controlled trial. Arch Phys Med Rehabil. 2018;99(5):834-842 e834. doi:10.1016/j.apmr.2018.01.023

18. Luque-Moreno C, Oliva-Pascual-Vaca A, Kiper P, Rodriguez-Blanco C, Agostini M, Turolla A. Virtual reality to assess and treat lower extremity disorders in post-stroke patients. Methods Inf Med. 2016;55 (1):89-92. doi:10.3414/ME14-02-0020

19. Kiper P, Turolla A, Piron L, et al. Rzeczywistość wirtualna $w$ rehabilitacji poudarowej - Badania, trening $i$ efekty terapii wirtualnej [Virtual reality for stroke rehabilitation: assessment, training and the effect of virtual therapy]. Rehabilitacja Medyczna. 2010;14 (2):23-32. doi:10.5604/01.3001.0009.3141

20. Jastrzebski D, Zebrowska A, Rutkowski S, et al. Pulmonary rehabilitation with a stabilometric platform after thoracic surgery: a preliminary report. J Hum Kinet. 2018;65:79-87. doi:10.2478/ hukin-2018-0044 
21. Garvey C, Bayles MP, Hamm LF, et al. Pulmonary rehabilitation exercise prescription in chronic obstructive pulmonary disease: review of selected guidelines: an official statement from the american association of cardiovascular and pulmonary rehabilitation. J Cardiopulm Rehabil Prev. 2016;36(2):75-83. doi:10.1097/HCR.0000000000000171

22. Viljanen A. Reference values for spirometric, pulmonary diffusing capacity and body plethysmographic studies. Scand J Clin Invest. 1982;42:1-50

23. Sliwinski P, Gorecka D, Jassem E, Pierzchala W. Polish respiratory society guidelines for chronic obstructive pulmonary disease. Pneumonol Alergol Pol. 2014;82(3):227-263. doi:10.5603/PiAP.2014.0030

24. Szczegielniak J, Latawiec KJ, Luniewski J, et al. A study on nonlinear estimation of submaximal effort tolerance based on the generalized MET concept and the 6MWT in pulmonary rehabilitation. PLoS ONE. 2018;13(2):e0191875. doi:10.1371/journal.pone.0191875

25. Paavola J, Oliver K, Ustinova K. Use of X-box kinect gaming console for rehabilitation of an individual with traumatic brain injury: a case report. Novel Physiotherapies. 2013;3:1

26. Tanaka H, Monahan KD, Seals DR. Age-predicted maximal heart rate revisited. J Am Coll Cardiol. 2001;37(1):153-156. doi:10.1016/ S0735-1097(00)01054-8

27. Jones C, Riklki R. Measuring functional fitness of older adults. J Aging Phys Act. 2002;25-30.

28. Greulich T, Koczulla AR, Nell C, et al. Effect of a three-week inpatient rehabilitation program on 544 consecutive patients with very severe COPD: a retrospective analysis. Respiration. 2015;90 (4):287-292. doi:10.1159/000436979

29. Casaburi R. Whither pulmonary rehabilitation? Will alternative modes help or hurt? Eur Respir J. 2018;52:4. doi:10.1183/13993003.01678-2018
30. Barry G, van Schaik P, MacSween A, Dixon J, Martin D. Exergaming (XBOX Kinect (TM)) versus traditional gym-based exercise for postural control, flow and technology acceptance in healthy adults: a randomised controlled trial. BMC Sports Sci Med R. 2016;8.

31. Egan C, Deering BM, Blake C, et al. Short term and long term effects of pulmonary rehabilitation on physical activity in COPD. Respir Med. 2012;106(12):1671-1679. doi:10.1016/j.rmed.2012.08.016

32. Gottlieb V, Lyngso AM, Nybo B, Frolich A, Backer V. Pulmonary rehabilitation for moderate COPD (GOLD 2)-does it have an effect? COPD. 2011;8(5):380-386. doi:10.3109/15412555.2011.610393

33. Roman M, Larraz C, Gomez A, et al. Efficacy of pulmonary rehabilitation in patients with moderate chronic obstructive pulmonary disease: a randomized controlled trial. BMC Fam Pract. 2013;14:21. doi:10.1186/1471-2296-14-21

34. Verrill D, Barton C, Beasley W, Lippard WM. The effects of short-term and long-term pulmonary rehabilitation on functional capacity, perceived dyspnea, and quality of life. Chest. 2005;128 (2):673-683. doi:10.1378/chest.128.2.673

35. LeGear T, LeGear M, Preradovic D, Wilson G, Kirkham A, Camp PG. Does a Nintendo Wii exercise program provide similar exercise demands as a traditional pulmonary rehabilitation program in adults with COPD? Clin Respir J. 2016;10(3):303-310. doi:10.1111/crj.2016.10.issue-3

36. Wardini R, Dajczman E, Yang N, et al. Using a virtual game system to innovate pulmonary rehabilitation: safety, adherence and enjoyment in severe chronic obstructive pulmonary disease. Can Respir J. 2013;20(5):357-361. doi:10.1155/2013/563861

International Journal of Chronic Obstructive Pulmonary Disease

Dovepress

\section{Publish your work in this journal}

The International Journal of COPD is an international, peer-reviewed journal of therapeutics and pharmacology focusing on concise rapid reporting of clinical studies and reviews in COPD. Special focus is given to the pathophysiological processes underlying the disease, intervention programs, patient focused education, and self management protocols. This journal is indexed on PubMed Central, MedLine and CAS. The manuscript management system is completely online and includes a very quick and fair peer-review system, which is all easy to use. Visit http://www.dovepress.com/testimonials.php to read real quotes from published authors. 